\title{
BIBLIA E INQUISICIÓN, CRIPTOJUDAÍSMO Y ALIMENTACIÓN EN LA ESPAÑA MODERNA
}

\author{
POR \\ VINCENT PARELLO ${ }^{1}$ \\ Universidad Bordeaux Montaigne
}

\section{RESUMEN}

Los marranos españoles y portugueses en la época moderna respetaban las leyes de la casherut que figuraban en el Éxodo, el Levítico y el Deuteronomio. Algunos lo hacían por fidelidad a la tradición familiar, otros por costumbre cultural, y otros todavía para seguir los ritos y los preceptos de la ley mosaica. Así renovaban el sello de su elección divina y tenían la impresión de formar parte del pueblo elegido que, desde Noé, había heredado las tres noblezas teologal, natural y civil.

PALABRAS CLAVE: Inquisición; Biblia; criptojudaísmo; casherout; España moderna.

\section{BIBLE AND INQUISITION, CRIPTOJUIDAISM AND FOOD IN THE MODERN SPAIN}

\begin{abstract}
In the Modern Spain, both Spanish and Portuguese Marranos respected the Cacherout featured in the Books of Exodus, Leviticus and Deuteronome. Their motivations were varied: family tradition, cultural tradition or Mosaic Law abiding. They thus felt like renovating the sign of divine election and their belonging to the chosen people, who, since Noah, had inerited theologal, civil and natural nobility.
\end{abstract}

KEY WORDS: Inquisition; Bible, crypto-judaism; cacherout; modern Spain.

CómO CITAR ESTE ARTículo / CITATION: Parello, Vincent. 2020. «Biblia e Inquisición, criptojudaísmo y alimentación en la España moderna». Hispania Sacra LXXII, 146: 403-408. https://doi.org/10.3989/hs.2020.028

\author{
Recibido/Received 17-01-2018 \\ Aceptado/Accepted 27-11-2018
}

En los edictos de fe publicados por la Inquisición española y portuguesa a lo largo de la época moderna, la materia alimenticia ocupa un lugar relevante en la caracterización del criptojudaísmo que los inquisidores calificaban de crimen de herejía y de apostasía (Flandrin 2002; Flandrin y Montanari 1996; Montanari 2009). A diferencia del edicto de gracia que tenía una intención puramente reconciliadora y redentora, el edicto de fe era, en palabras de Charles Amiel, "un inventario minucioso de las prácticas y de las afirmaciones heréticas acompañado de una llamada pública a la delación y de una amenaza de excomunión mayor para los que se hicieran el sordo" (Amiel 1993, 146). Dicha materia se articulaba mayormente en torno a tres fenómenos que eran las prohibiciones alimenticias previstas por la ley escrita (Torá) y la ley oral (Talmud), la abstinencia durante

1 parellov@gmail.com / ORCID iD: https://orcid.org/0000-0002-3948-8133 ciertas fiestas religiosas y el consumo de platos especiales según las circunstancias.

En virtud de las leyes sobre la alimentación llamadas en hebreo casherut, los judaizantes no podían comer animales vivos ni consumir sangre. Debían realizar el degüello ritual de las bestias, cortándoles el esófago y la traquea con un cuchillo afilado, degollar la carne poniéndola en remojo para que la sangre pudiera derramarse, descebarla y quitarle el nervio ciático en recuerdo del combate que Jacob libró contra el Ángel en el Antiguo Testamento (Jiménez Monteserín 1980, 505).²

2 «O que hayan purgado o desebado la carne que han de comer echándola en agua para la desangrar, o que hayan sacado la landrecilla de la pierna del carnero u de otra cualquier res. O que hayan degollado aves o reses que han de comer, atravesadas, diciendo "bendito sea el Señor que nos encomendó el degüello", catando primero el cuchillo en la uña por ver si tiene mella, cubriendo la tierra con sangre». El episodio de Jacob se encuentra en Génesis XXXII,33. 
Cuando el ayuno de Yom Kipur (Jiménez Monteserín 1980, 506), ${ }^{3}$ fiesta de expiación y de perdón; del ayuno de la reina Ester (ibíd., 507) ${ }^{4}$ que celebraba la victoria de los judíos sobre las tropas del rey persa Asuero; del ayuno del Rebeaso (ibíd., 507) ${ }^{5}$ que conmemoraba la doble destrucción del Templo de Jerusalén por el rey de Babilonia Nabucodonosor y por las legiones romanas del emperador Tito; así como durante los ayunos facultativos del lunes y del jueves, los criptojudíos debían abstenerse de beber y de comer entre el amanecer y el anochecer (ibíd., 507). ${ }^{6}$

El viernes por la tarde, víspera del shabat, se preparaba la adafina, especie de olla que se cocía a fuego lento durante casi toda la noche, para no tener que guisar el sábado (Jiménez Monteserín 1980, 505). ${ }^{7}$ Para celebrar la Pascua judía (Pésaj) y las fiestas de las Cabañuelas (Sucot), los judaizantes consumían pan cenceño y utilizaban vajía nueva (ibíd., 507). ${ }^{8}$ Después de los entierros, tomaban sus comidas detrás de la puerta, en el mismo suelo, y se alimentaban mayormente de pescado, de aceitunas y de huevos (ibíd., 510). ${ }^{9}$ Fuera de la observancia de las prácticas judías, los inquisidores señalaban la no observancia de la Cuaresma cristiana, que se traducía por el consumo de carne a lo largo de dicho periodo de abstinencia (ibíd., 505-506). ${ }^{10}$

De todas estas costumbres alimenticias, la que ha dejado más huellas en la vida española, era sin duda la interdicción de comer animales impuros, o sea de cualquier bestia que no tuviera la pezuña hendida y que formara parte de los rumiantes, así como la carne de cerdo, prohibición que, dicho sea de paso, era común al judaísmo y al islam (Jiménez Monteserín 1980, 512). ${ }^{11}$

\section{LAS LEYES ALIMENTICIAS EN LA BIBLIA}

Si las leyes sobre la alimentación siguen siendo, en la Torah y en el Talmud, reglas sin explicaciones, resulta sin embargo posible formular algunas hipótesis acerca de ellas.

3 «O que hayan ayunado el ayuno mayor que dicen del perdón, andando aquel día descalzos».

4 «O si ayunasen el ayuno de la reina Ester».

5 «O si ayunasen el ayuno del Rebeaso, que llaman del perdimiento de la Casa Santa».

6 «...u otros ayunos de judíos de entre semana, como el lunes o el jueves, no comiendo en los dichos días hasta la noche salida la estrella y en aquellas noches no comiendo carne y lavándose un día antes para los dichos ayunos».

7 «A la comida preparada de víspera para consumir el sábado se solía denominar adefina o adafina, y su empleo constituía muchas veces un rasgo definitorio de la condición judaica de quienes comían aquella especie de estofado cocido a fuego lento el día santo del sábado».

8 «O celebrasen la Pascua del pan cenceño, comenzando a comer lechugas, apio u otras verduras amargas en los tales días. O guardasen la Pascua de las Cabañuelas, poniendo ramos verdes o paramentos, comiendo y recibiendo colación, dándola los unos a los otros».

9 «... comiendo en el suelo, tras las puertas, pescado y aceitunas y no carne, por duelo del difunto, no saliendo de casa por un año por observancia de la dicha ley».

10 «O que hayan comido carne en Cuaresma y en otros días prohibidos por la Santa Madre Iglesia, sin tener necesidad para ello, teniendo y creyendo que lo podían comer sin pecado». Volvemos a encontrar exactamente lo mismo en el edicto de fe de la "Secta de Mahoma».

11 "Y que no coman tocino ni beban vino por guardia y observancia de la secta de los moros».
En primer lugar, estaban relacionadas con el concepto de pureza y la idea de santidad. Como lo señala Yves Durand, un pueblo es santo, en cuanto está separado de los demás pueblos por prohibiciones políticas, religiosas y alimenticias (Durand 1987, 33-35). Es lo que aparece a las claras en estos tres fragmentos sacados del Éxodo, del Levítico y del Deuteronomio:

Y hombres de santidad seréis para Mí, y carne destrozada para las fieras en el campo (o en cualquier lugar), a los perros la echaréis (Éxodo XXII,30).

Porque yo soy Jehová vuestro Dios; vosotros por tanto os santificaréis, y seréis santos, porque yo soy santo; así que no contaminéis vuestras personas con ningún animal que se arrastra sobre la tierra. Porque yo soy Jehová, que os hago subir de la tierra de Egipto para ser vuestro Dios: seréis, pues, santos, porque yo soy santo. Esta es la ley acerca de las bestias, y las aves, y todo ser viviente que se mueve en las aguas, y todo animal que se arrastra sobre la tierra (Levítico XI,44-46).

Ninguna cosa mortecina comeréis; al extranjero que está en tus poblaciones la darás, y él podrá comerla; o véndela a un extranjero, porque tú eres pueblo santo a Jehová tu Dios. No cocerás el cabrito en la leche de su madre (Deuteronomio XIV,21).

En segundo lugar, podían favorecer en el hombre el desarrollo de la autodisciplina y el dominio de los apetitos. También poseían virtudes higiénicas y humanitarias:

Maïmonide écrivait que l'observance des lois sur l'alimentation enseigne la maîtrise des appétits et la contrainte. Il avait également le sentiment que les aliments interdits étaient malsains. Le thème de l'hygiène a aussi été évoqué par d'autres. Certains ont soutenu qu'il y avait une base humanitaire aux lois sur l'alimentation: l'aversion pour le sang, l'exigence d'un abattage rapide et sans douleur, la consommation d'animaux uniquement herbivores inculquent la sensibilité envers les êtres vivants et réfrènent la violence (Wigoder 1998, 40).

Martin Harris formuló en 1985 la tesis según la cual la Biblia y el Corán prohibían el cerdo porque su crianza podía constituir una amenaza para los sistemas naturales y culturales de Medio Oriente. En efecto, en comparación con las ovejas y las cabras, los cerdos eran menos adaptados al hábitat árido de Mesopotamia y de Egipto (Harris 1985, 42-48).

Como ya lo señalamos, dos tabúes pesaban sobre la alimentación: la interdicción de comer seres muertos y sangre, considerada como sede del alma (néphésh):

Todo lo que se mueve y vive, os será para mantenimiento: así como las legumbres y plantas verdes, os he dado todo. Pero carne con su vida, que es su sangre, no comeréis. Porque ciertamente demandaré la sangre de vuestras vidas; de mano de todo animal la demandaré, y de mano de hombre; de mano del varón su hermano demandaré la vida del hombre (Génesis IX,2-4).

Si cualquier varón de la casa de Israel, o de los extranjeros que moran entre ellos, comiere alguna sangre, yo pondré mi rostro contra la persona que comiere sangre, y la cortaré de entre su pueblo. Porque la vida de la carne en la sangre está, y yo os la he dado para hacer expiación sobre el altar por vuestras almas; ya la misma sangre hará expiación de la persona. Por tanto, he dicho a los hijos de Israel: ninguna persona de vosotros comerá sangre, ni el extranjero que mora entre vosotros comerá sangre (Levítico XVII,10-11). 
Sólo cuídate de no comer la sangre, porque la sangre es la vida, y no comerás la vida con la carne. No la comerás; la derramarás como agua sobre la tierra... (Deuteronomio XII,23-24).

A estas dos prohibiciones, hace falta añadir la interdicción de cocer la carne del cabrito en la leche de su madre, interdicción que el Talmud extendió a la cocción de cualquier animal doméstico en la leche de cualquier otro animal doméstico. Esta medida fue sin duda concebida en un principio para impedir ciertas prácticas paganas que consistían en preparar hechizos cociendo los cabritos en la leche:

Lleva tus mejores primicias a la casa del Señor tu Dios. No cuezas ningún cabrito en la leche de su madre (Éxodo XXXIV,26).

No cocerás el cabrito en la leche de su madre (Deuteronomio XIV,21).

Por una parte, había los animales cuyo consumo estaba autorizado llamados tahor (puro); por otra, los animales prohibidos por la ley mosaica nombrados, según los casos, tamé (impuro), chèqets (abominable) o toévah (objeto de asco). En el Deuteronomio se elabora una frontera muy nítida entre lo puro y lo impuro:

Nada abominable comerás. Estos son los animales que podréis comer: el buey, la oveja, la cabra, el ciervo, la gacela, el corzo, la cabra montesa, el íbice, el antílope y el carnero montés. Y todo animal de pezuñas, que tiene hendidura de dos uñas, y que rumiare entre los animales, ese podréis comer. Pero estos no comeréis, entre los que rumian o entre los que tienen pezuña hendida: camello, liebre y conejo; porque rumian, mas no tienen pezuña hendida, serán inmundos; ni cerdo, porque tiene pezuña hendida, mas no rumia; os será inmundo. De la carne de éstos no comeréis, ni tocaréis sus cuerpos muertos. De todo lo que está en el agua, de estos podréis comer: todo lo que tiene aleta y escama. Mas todo lo que no tiene aleta y escama, no comeréis; inmundo será. Toda ave limpia podréis comer. Y estas son de las que no podréis comer: el águila, el quebrantahuesos, el azor, el gallinazo, el milano según su especie, todo cuervo según su especie, el avestruz, la lechuza, la gaviota y el gavilán según sus especies, el búho, el ibis, el calamón, el pelícano, el buitre, el somormujo, la cigueña, la garza según su especie, la abubilla y el murciélago. Todo insecto alado será inmundo; no se comerá. Toda ave limpia podréis comer. Ninguna cosa mortecina comeréis; al extranjero que está en tus poblaciones la darás, y él podrá comerla; o véndela a un extranjero, porque tú eres pueblo santo a Jehová tu Dios. No cocerás el cabrito en la leche de su madre (Deuteronomio XIV,4-20).

Hallamos consideraciones similares en el Levítico que enumera las aves y los insectos vedados:

De entre los animales, todo el que tiene pezuña hendida y que rumia, éste comeréis. Pero de los que rumian o que tienen pezuña, no comeréis estos: el camello, porque rumia pero no tiene pezuña hendida, lo tendréis por inmundo. También el conejo, porque rumia, pero no tiene pezuña, lo tendréis por inmundo. Asimismo la liebre, porque rumia, pero no tiene pezuña, la tendréis por inmunda. También el cerdo, porque tiene pezuñas, y es de pezuñas hendidas, pero no rumia, lo tendréis por inmundo. De la carne de ellos no comeréis, ni tocaréis su cuerpo muerto; los tendréis por inmundos. Esto comeréis de todos animales que viven en las aguas: todos los que tienen aletas y escamas en las aguas del mar, y en los ríos, estos comeréis. Pero todos los que no tienen aletas ni escamas en el mar y en los ríos, así de todo lo que se mueve como de toda cosa viviente que está en las aguas, los tendréis en abominación. Todo insecto alado que anda sobre cuatro patas, que tuviere piernas además de sus patas para saltar con ellas sobre la tierra; estos comeréis de ellos: la langosta según su especie; el avetruz, la lechuza, la gaviota, el gavilán según su especie; el argol según su especie, y el hagab según su especie. Todo insecto alado que tenga cuatro patas, tendréis en abominación (Levítico XI,3-21).

\section{Animales «puros» y «comestibles»}

\begin{tabular}{|l|}
\hline Buey \\
\hline Carnero \\
\hline Cabra \\
\hline Ciervo \\
\hline Gacela \\
\hline Corzo \\
\hline Cabra montesa \\
\hline Antílope \\
\hline Búfalo \\
\hline Ibice \\
\hline Pez con aletas y escama \\
\hline Saltamonte \\
\hline Soleâm \\
\hline Khargôl \\
\hline Khagab \\
\hline
\end{tabular}

Animales «impuros» y «no comestibles»

\begin{tabular}{|l|}
\hline Damán \\
\hline Liebre \\
\hline Camello \\
\hline Cerdo \\
\hline Pez sin aletas y escama \\
\hline Aguila \\
\hline Quebrantahuesos \\
\hline Grifo \\
\hline Azor \\
\hline Buitre \\
\hline Cuervo \\
\hline Avestruz \\
\hline Gaviota \\
\hline Gavilán \\
\hline Buho \\
\hline Cormorán \\
\hline Cisne \\
\hline Alcatraz \\
\hline Cigüeña \\
\hline Garza \\
\hline Abubilla \\
\hline Murciélago \\
\hline Insecto de cuatro patas \\
\hline Topo \\
\hline Ratón \\
\hline Lagarto \\
\hline Geco \\
\hline Tortuga \\
\hline Salamandra \\
\hline Ciempiés \\
\hline Camaléon \\
\hline
\end{tabular}


La carne casher era la que se obtenía tras el degüello ritual llamado en hebreo shehitá. Debía hacerse cargo de él un matarife (shohet) confirmado por una autoridad rabínica fehaciente.

El ritual se componía de varias etapas. Empezaba por una bendición cuya huella encontramos en el edicto de fe español y que consistía en bendecir a Jehová: "bendito sea el Señor que nos encomendó el degüello». Proseguía con la jugulación rápida de la hoja en la garganta del animal, el enganche de la bestia a una cuerda, boca abajo, para que pudiera vaciarse de su sangre. Al final se quitaba el nervio ciático y la grasa, y se ponía la carne en remojo para que acabara de evacuarse de su sangre. Una hoja de cuchillo defectuosa o una pausa en el momento de la jugulación podía acarrear ipso facto la anulación de la shehitá En España, hasta la fecha de la expulsión de 1492, las aljamas determinaban un impuesto comunitario para financiar los servicios del shohet y mantener una shehitá conforme a la ley prescrita por la Mishná y el Talmud. En efecto, no se encuentra en la ley escrita ninguna descripción detallada del ritual, salvo estas líneas del Deuteronomio: «Si el lugar que el Señor tu Dios escoge para poner su nombre está muy lejos de ti, entonces podrás matar de tus vacas y de tus ovejas que el Señor te ha dado, como te he ordenado, y podrás comer dentro de tus ciudades todo lo que desees» (Deuteronomio XII,21).

\section{CRIPTOJUDAÍSMO Y ALIMENTACIÓN}

A ojos de los guardias de la fe, los ritos alimenticios debían considerarse e interpretarse a la luz de la herejía. Se convirtieron para la Inquisición en señales de criptojudaísmo, en sinónimo de individuos sospechosos que, más allá del bautismo, seguían observando los preceptos y los ritos de la ley mosaica, es decir, la que Dios había sellado con Moisés en el Monte Sinai (Beinart 1983, 266; Révah 1959-1960). ${ }^{12}$

Por su formación de jurista, los inquisidores no eran expertos en materia de teología, y, aún menos, en materia de judaísmo. Muy a menudo, en efecto, daban una interpretación religiosa a prácticas que eran ante todo culturales. Se comía tal o cual plato porque los padres, los abuelos y los bisabuelos lo comían, por costumbre y por tradición. Los archivos inquisitoriales encierran numerosas consideraciones acerca de la comida, y tienen por lo tanto un valor de documentos etnográficos y folklóricos.

Entre los platos típicamente conversos, figuraba la adafina, que significaba comida caliente. La composición de dicho plato, típico del shabat, variaba según las regiones y las épocas. En Cataluña, se componía de espinacas, de garbanzos, de habas y de cebollas; en Ciudad Real y en gran parte de Andalucía, de pescado y de berenjenas; y en Murcia, de garbanzos, de arroz y de mucho aceite. En Canarias, estaba constituido de carne de cabra, guisada con cebollas y aceite (Blázquez Miguel 1988, 59-60).

Los judaizantes de Ciudad Real se valían de todo tipo de trampas y de ardides para no despertar las sospechas de sus

12 «... que lo fisiesen e guardasen secreto que no fuesen vistos ni entendidos por los christianos por mejor permanesçer en sus herrores y heregias, creyendo que por aquello se avian de salvar». vecinos cristianos viejos (Beinart 1983, 225-300). Enviaban a sus criados a comprar carne en el matadero municipal pero, en la intimidad del hogar, la daban de comer a los cerdos o a los perros. Cocinaban en dos sartenes distintas: la una con manteca, la otra con aceite de oliva, para que la grasa de cerdo enmascara el olor del aceite virgen. Los viernes, las mujeres preparaban dos platos: un plato de carne para su manjar sabático y un plato de pescado, por si algún cristiano viejo viniera a darles una visita. Cuando alguien llamaba a la puerta, el primer reflejo de Catalina de Zamora era esconder la adafina; sólo era cuando identificaba claramente al huésped cuando le convidaba a compartir su propia comida (Beinart 1983, 225-300). A donde fuera, Juan González se desplazaba con sus cubiertos y su propio vaso (ibíd., 3, 235).

Antes de la fecha de la expulsión, eran los judíos quienes se encargaban de degollar ritualmente los animales y las aves. En 1459 y 1460, Maestre Angel, judío de Guadalajara, desempeñaba el papel de matarife ritual en casa del recaudador de impuestos Juan de Fez. De la misma manera que los judaizantes se reunían en domicilios privados para observar el shabat, hacían realizar la shehitá por un fiel observante de la ley de Moisés.

Gracias a la documentación del tribunal de Ciudad RealToledo, Haim Beinart ha podido reconstituir la lista de los principales matarifes de la ciudad durante la segunda mitad del siglo XV. Se realizaban degüellos rituales en los patios de Diego Díaz, mercader de especias, de Juan Díaz, apodado Juan Dinela, de Juan Falcón el Viejo, de Rodrigo Verenjena, de Alvaro Carrillo, de Juan González Escogido, de Lope Franco, de Juan López Panpán, de García Barbas, sastre, de Rodrigo Ataranchón, de Juan de Fez, de Alonso González de los Olivos, de Pero Franco, de Rodrigo Varsano, de Juan Martínez de Olivos y de su hijo Alvar García de los Olivos, de Pedro Gómez, platero, del marido de Constanza Díaz, de Alonso de Herrera el Largo, de Rodrigo Marín, notario y de Rodrigo Carestia (Beinart 1983, 284-285). El número muy elevado de chohet (21 en conjunto) nos indica hasta qué punto esta práctica estaba muy difundida entre las familias cristianas nuevas de Ciudad Real.

Albert Bensoussan (2014) refiere que uno de sus amigos, el poeta Jaume Vidal Alcocer, natural de Manacor y descendiente de xuetes, es decir judíos convertidos colectivamente en Mallorca a fines del siglo XV, le había dicho que en su familia se comía por la fiesta de Pascua una torta de pan cenceño... icon una lonja de cecina encima! De la misma manera Angela Selke $(1980,40)$ explica que la sobresada, embutido de los Baleares, era una pura invención de los xuetes. En efecto, era una salsicha que ponía de realce el cerdo, enmascarando su sabor con pimentón fuerte y hierbas aromáticas (romero, tomillo, orégano...).

En un artículo de 1965, Albert Sicroff aborda el descubrimiento de focos de judaizantes en el monasterio jerónimo de Guadalupe durante el año 1485 (Sicroff 1965, 397-422). Se acusaba a ciertos monjes de respetar los mitzvot, mayormente las prohibiciones alimenticias, de despreciar los ayunos cristianos y la Cuaresma, de obstaculizar la actividad de la Inquisición y de poner en tela de juicio la existencia del Santo Oficio. Como lo explica Sophie Coussemacker, dicho escándalo hizo mucho ruido en el monasterio y allende:

L'effet produit par la découverte de ces judaïsants fut immédiat: craignant les conséquences du scandale 
pour leur réputation, les Hiéronymites décidèrent d'adopter un statut de pureté de sang qui fermait, provisoirement, l'entrée de l'ordre aux convertis et à leurs descendants. En parallèle, le général étendit I'inquisition à tous les monastères. Le statut et la "reinquisición» de l'ordre selon la formule de Sigüenza, sont l'aboutissement d'un très net raidissement des Hiéronymites vis-à-vis des convertis, après 1485 . Cependant, les partisans de la tolérance étaient encore nombreux (Coussemacker 1991, 15).

Pedro López, cura de la iglesia de San Salvador fue condenado por la Inquisición de Cuenca en 1488. El fiscal le acusaba, entre otras cosas, de comer carne y lechón el sábado, detalle que parece por lo menos curioso tratándose de un cristiano nuevo de judío, de no comer carne trefá, o sea que no había sido matada según el ritual de la shehitá, y de haber afirmado que acogía la hostia en su boca como un manjar cualquiera. Para su defensa, el acusado alegaba que, durante muchos años, había padecido fiebre cuartana y dolores en el costado, razón por la cual no siempre había podido respetar las normas dietéticas impuestas por la autoridad eclesiástica. Después de haber sufrido tormento, abjuró sus errores y fue condenado el 26 de noviembre de 1490 a estar encerrado en el monasterio trinitario de San Jorge para hacer penitencia (Carrete Parondo 1979, 52-53).

Asimismo, Fernando de la Barrera, sacerdote de la parroquia de San Salvador fue condenado por el tribunal de Cuenca en 1491. En su confesión, explicaba que si había comido carne durante la Cuaresma, era por motivos puramente médicos, porque siempre había tenido problemas de riñón y de estómago y una úlcera en la garganta. Si había frecuentado don Simuel Abén Xurén, médico del marqués de Villena y don Isaac Cohen, médico de la ciudad de Huete, era más que nada por razones de salud. Los testigos de la acusación no lo veían de la misma manera. En su opinión, se trataba de un cura judaizante, orgulloso de sus orígenes conversos, que estaba en contacto con las comunidades judías de Cuenca y de su región para observar el shabat y otras fiestas religiosas. Según varios vecinos de la villa de Huete, recurría a judíos para matar ritualmente los animales y las aves, comía a su mesa e incitaba a los cristianos a que comieran alimentos casher. Fernando de la Barrera no tuvo la misma suerte que su colega. El 21 de diciembre murió en la hoguera tras haber sido excomulgado (Carrete Parondo 1979, 55-61). ${ }^{13}$

Diego de Alba, corregidor de la villa de Cuéllar, fue condenado por la Inquisición en 1498. Por sus numerosas responsabilidades administrativas al servicio del duque de Albuquerque, Beltrán de la Cueva, y sus responsabilidades políticas como primer magistrado de la villa, se había

13 «Como cura del pueblo, hasía matar carne a judío para que comiese el común e gente popular por los hacer pecar y judaizar, e aun por los mejor atraer a ellos desía que non avía mejor carne que la que degollaban el judío, e ansí la procurava de comer con esta ceremonia disiendo: "Pluguiera a Dios que me hiziera tan dichoso que pudiera yo degollar la vianda que tengo de comer syn buscar judío para me la degollar". Don Simuel Alori, arrendador y vecino de Huete, declaró que tenía las rentas de Villar de Sas de Don Guillén, a causa de lo qual algunas veces por espacio de quatro meses, ocasión que aprovechó para, mediante la intervención del clérigo procesado, comprar carne y degollarla según el rito mosaico, luego, mientras la comían, el acusado la alababa». granjeado enemigos tanto en la comunidad judía como en las comunidades conversas y cristianas. Se le acusaba de haber tenido familiaridad con los judíos, de haber comido su carne y bebido su vino, de purgar y de descebar la carne según la costumbre judía (Rábade Obradó 2006, 348).

Andrés González de Alía también fue condenado por la Inquisición en 1486. En su primera confesión, indicó haber sido iniciado en el criptojudaísmo por Gonzalo Marqués, vecino de Alcaudete, con cuya hija Isabel se casó. Como cristiano, había renegado la ley de Cristo observando los ritos y los preceptos de la ley mosaica, y como eclesiástico -sacerdote en las localidades de Herrera y de Alcaudete- había quebrantado el voto de castidad (Rábade Obradó 2013, 124-125).

A finales del reinado de Felipe II, por los años 1588-1592, los inquisidores de Cuenca y de Toledo desmantelaron en la localidad de Quintanar de la Orden, una red de judaizantes autóctonos que seguían practicando oficiosamente la religión de sus antepasados en una época en que el Santo Oficio se había puesto al servicio de la Contrarreforma para castigar los delitos de los cristianos viejos e impedir la penetración de las ideas protestantes en la península ibérica (Amiel 2001).

Al margen de las reglas alimenticias, los miembros de la familia Mora observaban al pie de la letra las reglas de pureza ritual que consistían en cortarse las uñas de las manos y de los pies, en lavarse todo el cuerpo (tebilá) o las manos únicamente (netilat yadayim) antes de sentarse a la mesa o de rezar, durante las fiestas, en periodo de regla, después de haber tocado un muerto, etc. Francisca, Luisa e Isabel de Mora, volvían las escudillas boca abajo después de haberlas lavado «porque no las lamiesen los perros, ni los gatos, porque por ser animales inmundos era prohibido en la dicha ley» (Parello 2001, 403). Obligados a vivir en un medio hóstil, los judaizantes tenían que hablar en cifra y utilizar un doble lenguaje. A modo de ejemplo, el adjetivo limpia significaba "olla que no había tenido cerdo", y el adjetivo sucia su contrario, "olla que había llevado cerdo". Es lo que apuntaba el fiscal, el licenciado Joan de Ochoa, en su acusación criminal del 24 de octubre de 1597 contra Francisca de Mora, esposa de Hernando de Sauca:

No comía [Francisca de Mora] tocino ni lo echaba en la olla de que havia de comer, y convidando a cierta persona de su casta y generación una vez a comer de su olla, le dixo que bien podía comer della que limpia estaba, dando a entender por las dichas palabras que no tenían tocino, lenguaje secreto y ordinario entre los que que de la dicha villa del Quintanar han guardado y vivido en la ley de Moisés.

...aviendo conbidado a comer a una de las dichas personas, le avía hecho lavar las manos primero que comiese, diziéndola que bien pudiera comer de su olla y que estaba limpia, dándole a entender que no tenía tocino, el qual lenguaje y modo de dezir avía sido muy usado y guardado entre ella y las demás personas de su profesión para significar en cifra quanto no tenía tocino la olla y el dezir que estaba sucia quando le tenía (Parello 2001, 404-405). ${ }^{14}$

\footnotetext{
14 Archivo Diocesano de Cuenca (en adelante ADC), Inquisición,
} legajo 314, expediente 4555 (1597). 
Entre los Mora, el degüello ritual daba lugar a verdaderas reuniones familiares. Antonio, hijo de Juan de Mora había matado una oveja en el patio de la casa de su hermano Francisco Martínez de Mora «atravesándole el cuchillo por la nuez». Después, la había comido en compañía de su tío Diego de Mora y de su mujer María de Villanueva y varios primos. A veces incluso, los Mora convidaban comensales moriscos a su mesa que venían a compartir con ellos «la carne muerta según la ceremonia de la ley de Moisés» (Parello 2001, 409). ${ }^{15}$

En los años 80 del siglo XVI, con la unión dinástica de las coronas de Castilla y de Portugal bajo el reinado de Felipe II, muchos marranos portugueses vinieron a probar su suerte en España. En la Mancha, su llegada suscitó la desconfianza y el recelo de las poblaciones cristianas viejas que, muy a menudo, se extrañaban de sus prácticas culturales. En casa de Isabel Fernández, vecina de Santa María del Campo, se barría al revés, se amasaba el pan de otra manera, y se despellejaban las aves con las manos y no con un cuchillo. ${ }^{16} \mathrm{En}$ un testimonio inquisitorial contra Francisco Hernández, instalado en el pueblo de Buenache de Alarcón, puede leerse el asombro de los habitantes del pueblo frente a esta familia portuguesa que guisaba con aceite de oliva, fumaba la carne en la chimenea y imartirizaba a perros por la Cuaresma! ${ }^{17}$

Como hemos evidenciado, los marranos españoles y portugueses en la época moderna respetaban las leyes de la casherut que figuraban en el Éxodo, el Levítico y el Deuteronomio. Algunos lo hacían por fidelidad a la tradición familiar, otros por costumbre cultural, y otros todavía para seguir los ritos y los preceptos de la ley mosaica.

En suma, si los judaizantes practicaban en público formas de religiosidad cristiana, en la intimidad de sus hogares seguían practicando el judaísmo y observando fiestas religiosas, reglas alimenticias, prácticas higiénicas y ritos relacionados con el nacimiento y la muerte. Así renovaban el sello de su elección divina y tenían la impresión de formar parte del pueblo elegido que, desde Noé, había heredado las tres noblezas teologal, natural y civil. Como muchos cristianos nuevos, Beatriz, hija de Hernando de Mora declaraba ante los inquisidores de Cuenca que «todas sus conversaciones eran del Antiguo Testamento, de las profecías de la llegada del Mesías y de la fecha en que Dios había dado la ley a Moisés». ${ }^{18} \mathrm{Al}$ fin y al cabo, la alimentación era reveladora de unas costumbres, de una cultura y de una religión.

\section{BIBLIOGRAFÍA}

Amiel, Charles. 1993. "Crypto-judaïsme et Inquisition. La matière juive dans les édits de la foi des Inquisitions ibériques». Revue de I'Histoire des Religions CCX, 2: 145-168.

Amiel, Charles. 2001. "Les cent voix de Quintanar. Le modèle castillan du marranisme». Revue de l'histoire des religions 218 (2): 195-280.

Beinart, Haim. 1983. Los conversos ante el tribunal de la Inquisición. Barcelona: Riopiedras.

Bensoussan, Albert. 2014. "Les marranes». Atalaya 14. https://doi. org/10.4000/atalaya.1330

Blázquez Miguel, Juan. 1988. Inquisición y criptojudaísmo. Madrid: Kaydeda.

Carrete Parondo, Carlos. 1979. «La Inquisición y los clérigos judaizantes de Cuenca (1489-1491)». Helmantica XXX: 51-61.

Coussemacker, Sophie. 1991. "Convertis et judaïsants dans l'ordre de Saint-Jérôme. Un état de la question». Mélanges de la Casa de Velázquez XXVII (2): 5-27.

Durand, Yves. 1987. Les solidarités dans les sociétés humaines. París: PUF.

Flandrin, Jean-Louis. 2002. L'ordre des mets. París: Odile Jacob.

Flandrin, Jean-Louis y Massimo Montanari. 1996. Histoire de l'alimentation. París: Fayard.

Harris, Martin. 1985. Vacas, cerdos, guerras y brujas. Los enigmas de la cultura. Madrid: Alianza.

Jiménez Monteserín, Miguel. 1980. Introducción a la Inquisición española. Documentos básicos para el estudio del Santo Oficio. Madrid: Editora Nacional.

Montanari, Massimo, 2009. Le manger comme cultura. Bruxelles: Université de Bruxelles.

Parello, Vincent. 2001. «Los Mora de Quintanar de la Orden: un criptojudaísmo familiar a finales del siglo XVI». Sefarad 61 (2): 395-418. https://doi.org/10.3989/sefarad.2001.v61.i2.590

Rábade Obradó, María Pilar. 2006. "Sobrevivir a la Inquisición: el proceso de Diego de Alba (1497-1498)». En la España medieval 29: 347-357.

Rábade Obradó, María Pilar. 2013. «La vida ante la Inquisición: biografía y procesos inquisitoriales en Castilla a fines del Medievo». Erebea 3: 117-134.

Révah, Israël Salvator.1959-1960. "Les marranes». Revue des études juives CXVIII: 29-77.

Selke, Angela. 1980. Vida y muerte de los Chuetas de Mallorca. Madrid: Taurus.

Sicroff, Albert, 1965. "The Jeronymite monastery of Guadalupe in 14th and 15th century Spain». En Collected Studies in honor of A. Castro's eightieth year, 397-422. Oxford.

Wigoder, Geoffrey. 1998. Dictionnaire encyclopédique du judaïsme. París: Laffont.

15 ADC, Inquisición, legajo 324, expediente 4652 (1592).

16 ADC, Inquisición, legajo 338, expediente 4837 (1594).

17 ADC, Inquisición, legajo 335, expediente 4790 (1593). Como lo dice Joan Corominas, en la época moderna los cristianos empleaban el término "perro» para designar a los musulmanes que vivían fuera de España.

18 ADC, Inquisición, legajo 318, expediente 4586. 